\title{
CORE DESIGN ACTIVITIES OF THE VERSATILE TEST REACTOR - CONCEPTUAL PHASE
}

\author{
F. Heidet ${ }^{1}$, and J. Roglans-Ribas ${ }^{1}$ \\ ${ }^{1}$ Argonne National Laboratory \\ 9700 South Cass Ave, Lemont, IL 60439 \\ fheidet@anl.gov
}

\begin{abstract}
The Versatile Test Reactor (VTR) is a new fast spectrum test reactor being developed in the United States under the direction of the US Department of Energy, Office of Nuclear Energy. The VTR mission is to enable accelerated testing of advanced reactor fuels and materials required for advanced reactor technologies. This includes neutron irradiation capabilities which would support alternate coolants including molten salt, lead/lead-bismuth eutectic mixture, gas, and sodium. The VTR aims at addressing most of the needs of the various stakeholders, which is primarily composed of advanced reactor technologists, developers and vendors, as well as a number of others interested parties.

Design activities are underway targeting a first criticality date by 2026, with General Electric recently joining the project to contribute to the VTR plant design. Current efforts are focused on all aspects of the VTR design, with the core design being at the center of the initial steps. The VTR is currently proposed as a 300 MWth sodium-cooled fast reactor able to reach peak fast flux levels in excess of $4.0 \times 1015 \mathrm{n} / \mathrm{cm} 2-\mathrm{s}$ (and total flux level of about $6.0 \times 1015 \mathrm{n} / \mathrm{cm} 2$ $\mathrm{s})$. In this configuration, it is using ternary metallic fuel with reactor-grade plutonium and $5 \%$ low-enriched uranium.
\end{abstract}

KEYWORDS: versatile test reactor, reactor design, advanced reactors, sodium-cooled fast reactor

\section{INTRODUCTION}

The Versatile Test Reactor (VTR) is a program supported by the United States Department of Energy (US-DOE) aiming at designing and building a fast-spectrum test reactor to bridge capability gaps related to accelerated fuels and materials testing and qualification for nuclear applications. In its current conceptual design stage, the VTR is a $300 \mathrm{MW}_{\text {th }}$ sodium-cooled fast reactor of the pool type. It will not generate electricity as to avoid competing secondary missions which could divert it from its primary mission, that is irradiation testing. The heat generated will be released to the air through several air-dump heat exchangers, conceptually similar to those used for the Fast Flux Test Facility (FFTF). The overall plant design for the VTR is based on the PRISM Mod-A reactor, designed by GE Hitachi Nuclear Energy [1]. VTR will be able to concurrently support development of several reactor technologies by providing a wide range of irradiation services. In particular, VTR will allow for use of coolants types different from the primary coolant in designated test locations, allowing it to provide value to a wide range of advanced reactors designs. 
This paper provides a short summary of the VTR project status in Section 2. This is followed by a detailed description of the VTR core design and of its performance characteristics in Section 3. The steady-state reactor performance characteristics as well as the reactivity control performance are discussed.

\section{VTR PROJECT STATUS}

The VTR program started in 2017 under the auspices of the US-DOE Office of Nuclear Energy (DOENE). The objectives are to bridge a capability gap (high-flux fast spectrum neutron irradiation) for the nuclear industry in the U.S. While the U.S. had been pioneering the demonstration of fast-spectrum reactors in the early age of nuclear energy, notably with EBR-II and FFTF, no reactor currently operating in the U.S. can offer significant fast flux levels. Fast flux is very important for irradiation testing as it allows achieving material damage much faster and can reduce the irradiation time needed to study new materials by over one order of magnitude. With the growing interest in advanced reactors, irradiation needs are increasing, making having the capability to perform accelerated fuels and materials testing of the upmost importance.

The mission of the VTR program is to help accelerate the testing of advanced nuclear fuels, materials, instrumentation, and sensors. It will also allow DOE to modernize its essential nuclear energy research and development infrastructure, and conduct crucial advanced technology and materials testing necessary to re-energize the U.S. nuclear energy industry. The timeline envisioned by the VTR program is to complete the construction of the reactor and start its operation by 2026. The reason for this accelerated schedule is to enable establishing this much-needed capability in time to support most advanced reactor technologies being currently developed.

The VTR objectives are to offer the following capabilities:

- $\quad$ Fast flux in excess of $4 \times 10^{15} \mathrm{n} / \mathrm{cm}^{2}$-s;

- $\quad$ Very high dpa level, in excess of $30 \mathrm{dpa} /$ year;

- $\quad$ Test volumes in excess of 7 liters per test location;

- $\quad$ Large number of potential test locations;

- $\quad$ Effective testing heights of at least $60 \mathrm{~cm}$;

- Ability to test fuel and material in prototypical environments other than sodium. This includes, but is not limited to, lead, lead-bismuth, helium and molten salts.

In 2018 the VTR program became a design project under the DOE Order 413.3B [2] that governs the management of capital acquisition projects. This directive is the process through which the DOE can enable the acquisition or construction of capital assets. This is a reflection of the intent to ensure the VTR program is being managed in accordance with the expectation set forth for a construction project. In particular, the purpose of this directive is "to provide the DOE with program and project management direction for the acquisition of capital assets with the goal of delivering projects within the original performance baseline, cost and schedule, and fully capable of meeting mission performance, safeguards and security, and environmental, safety, and health requirements unless impacted by a directed change". 


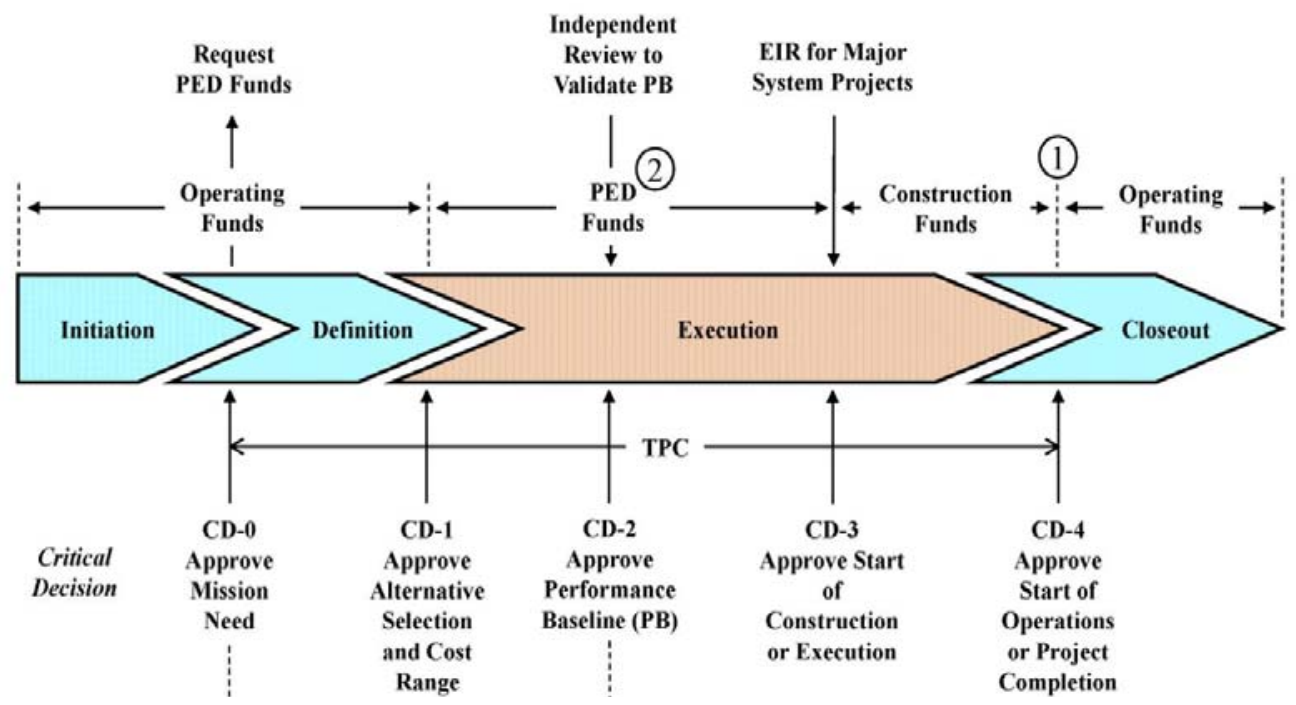

Figure 1. Critical decision chart as part of DOE directive 413.3B (Source: DOE)

In practice, by becoming a project, the VTR program must deliver on a number of critical decision (CD) points to approve the project from the design stage to final construction and operation. The five required CD points are presented in Fig. 1. CD-4 is the last one and would correspond to the start of operations for the VTR. The VTR program has successfully completed the CD-0 phase in February 2019 [3] and is now aiming at CD-1 which is planned to be completed during U.S. fiscal year 2020.

\section{DESIGN ACTIVITIES}

\subsection{Early Determinations}

The core design efforts for the VTR program have been initiated in the early stages of the program. Initial efforts focused on narrowing down the design space, in particular with respect to the core power level, and types of fuels that would allow achieving the performance objectives stated in Section 2. These early studies have been detailed in previous publications [4] and therefore only the major outcomes are mentioned here. Fig. 2 provides a summary of the results, showing the approximate minimum core power level required to achieve a particular peak fast flux level for various types of fuels. 


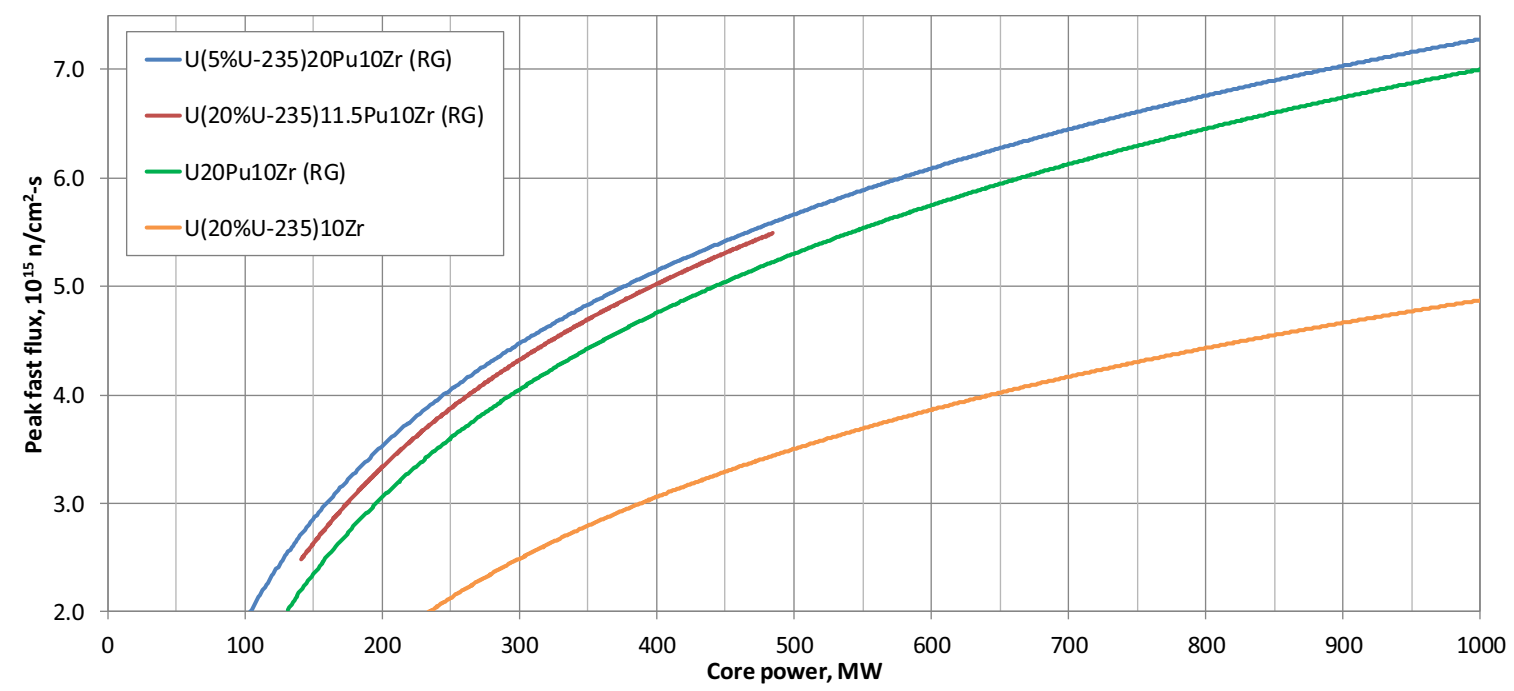

Figure 2. Required Core Power vs. Peak Fast Flux

These results indicated that with metallic fuel bearing plutonium the required core size could be limited to $300 \mathrm{MW}_{\text {th }}$ or less, but that if only high-assay low-enriched uranium is available then the core size would need to be at least $650 \mathrm{MW}_{\text {th. }}$ Based on these early results, the preferred fuel form for the VTR core design activities is the ternary $\mathrm{U}-20 \mathrm{Pu}-10 \mathrm{Zr}$, using reactor-grade plutonium and $5 \% \mathrm{LEU}$. The $20 \mathrm{wt} \%$ plutonium is determined based on the existing irradiation database for similar fuel, and the $5 \%$ uranium enrichment is based on the current enrichment capabilities in the U.S. This this is the preferred fuel forms, some efforts were made on exploring other potential fuel forms $[5,6]$.

A number of other early decisions were made with respect of the reactor design, such as to have the VTR being a pool-type reactor, with no energy conversion capabilities. Selection of the technologies supporting the VTR, not discussed in this paper, are primarily driven by leveraging demonstrated and low-risk technologies in order to minimize the overall project risk and meet the desired design and deployment timeline.

\subsection{Core General Overview}

Going from the pre-conceptual into the conceptual design phase, the VTR core has been refined, with more details included in the models, with a number of parameters adjusted based on interaction with the various VTR teams, such as the fuel, engineering and safety teams. The overall core layout remained the same, shown in Fig. 3, with 66 fuel assemblies, six control rods, three safety rods, 114 radial reflectors, 114 radial shield reflectors, and 10 shown test locations. The maximum power it is intended to generate remained $300 \mathrm{MW}_{\text {th. }}$. There will be up to five instrumented test locations as shown in Fig. 3, which means that experiments needing instrumentation will only be able to be inserted in one of these predetermined locations. Other test locations, referred to as non-instrumented test locations, could be positioned anywhere in the core, and their number can vary. This means that the performance reported in this document pertain to the specific configurations shown in Fig. 3, and if non-instrumented test locations were to be located in different positions these performance characteristics would be slightly different. The same remark also extends to the contents of the loaded experiments. With different experiments loadings expected each operating cycle, the core performance characteristics will slightly vary and differ from those presented here. However, VTR being fast reactor, the sensitivity of performance characteristics to the detailed loading arrangement is limited. 


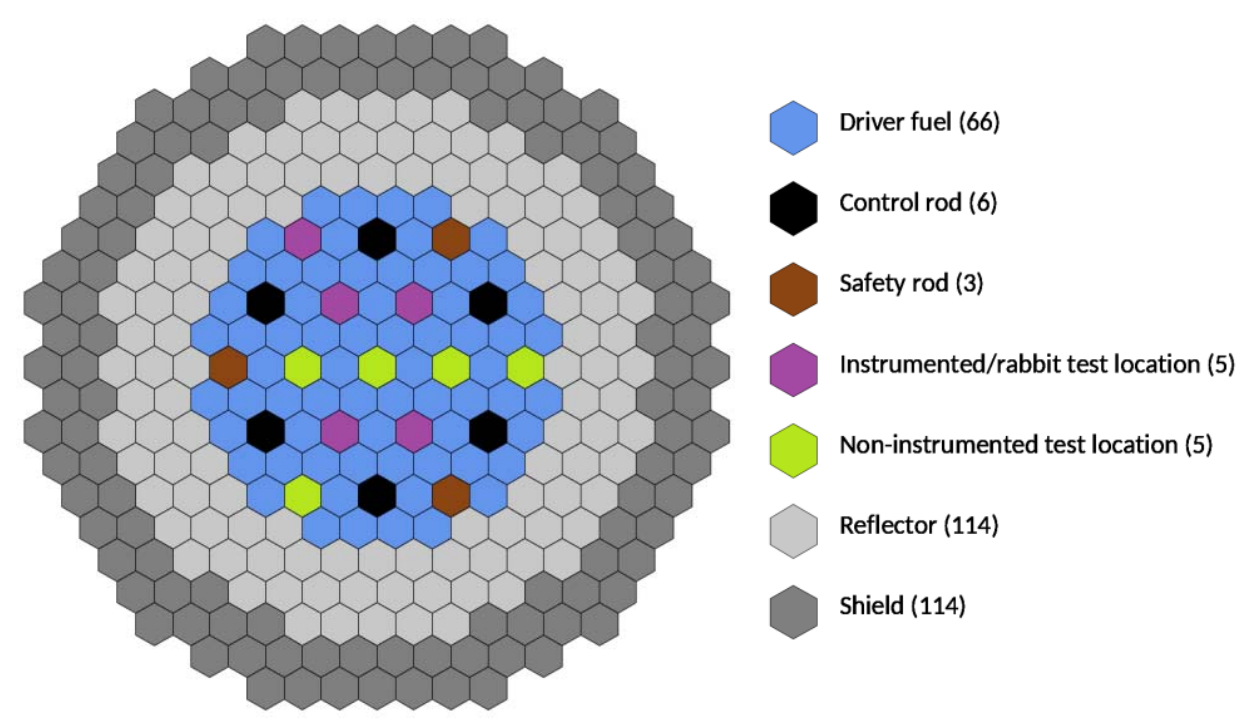

Figure 3. VTR core layout

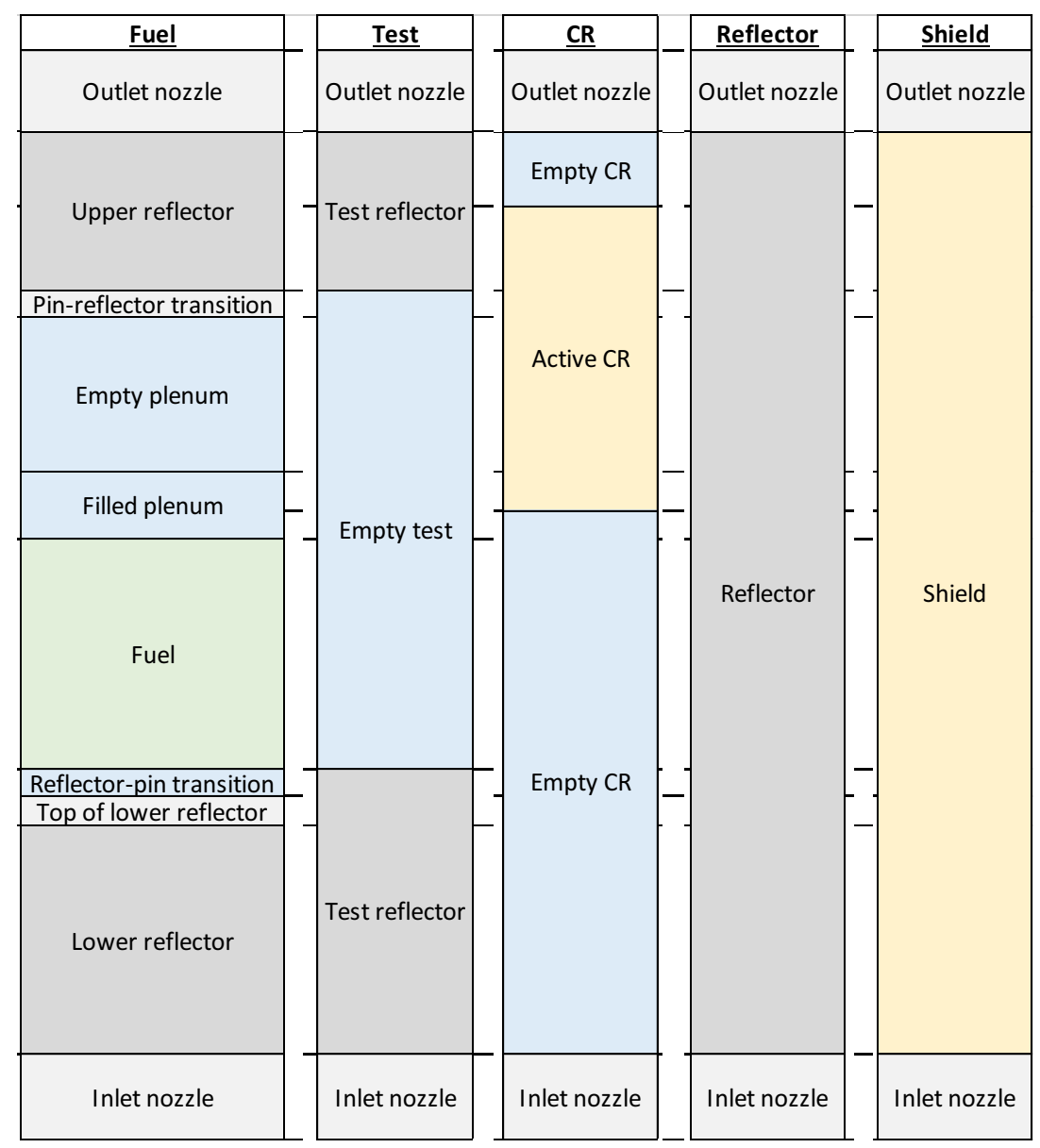

Figure 4. Axial Layout of the VTR Assemblies 
The overall length of each assembly from the extremity of the inlet nozzle to the extremity of the outlet nozzle is about 3.8 meters. The various regions currently modeled for each type of assembly is schematically represented in Fig. 4. At the current stage of the design, geometry details have only be determined for the fuel and control rod (CR) assemblies as these are the most impactful assemblies with respect to core performance.

\subsection{Neutronics Performance Characteristics}

The performance characteristics of the reference VTR core have been determined for an equilibrium cycle using the Argonne Reactor Computational code suite [7]. Transport theory with the P5 flux approximation was used with the ENDF/B-VII.0 nuclear database. The assumed fuel management strategy used to approach equilibrium conditions is illustrated in Fig. 5. The 12 central most fuel assemblies remain in the core for 3 cycles, the next 18 fuel assemblies remain in the core for 4 cycles, the following 12 fuel assemblies remain in the core for 5 cycles, and the remaining 24 assemblies remain in the core for 6 cycles. This is identified in Fig. 5 by the number in each assembly.

The reactor physics performance characteristics are provided in Table 1 for the equilibrium cycle. The "test peak fast flux" corresponds to the average fast flux achieved in a $20 \mathrm{~cm}$ tall section in the central test assembly. The "absolute peak fast flux" is the value achieved locally anywhere in the core. The maximum absolute/relative power variations correspond to the largest absolute/relative power variations observed in any fuel assembly between the beginning of an equilibrium cycle (BOEC) and the end of an equilibrium cycle (EOEC).

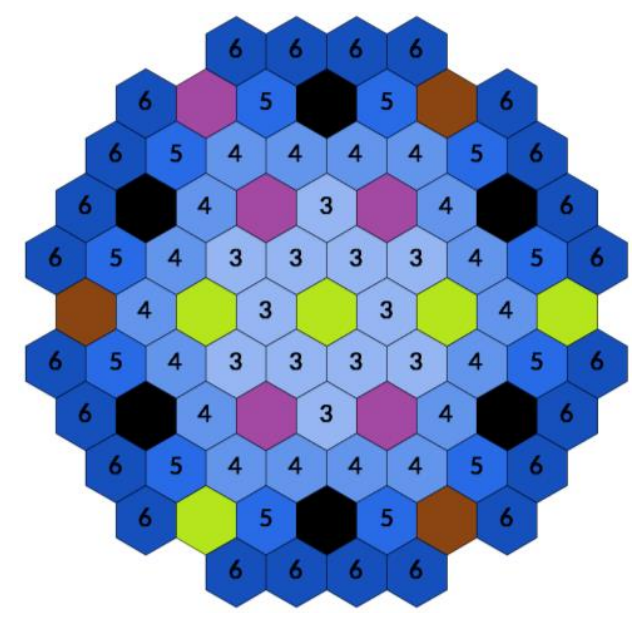

Figure 5. Fuel Management Scheme

The required plutonium weight fraction for the model used is a little larger than the target value of $20 \mathrm{wt} \%$. In practice, the fuel will be manufactured with $20 \mathrm{wt} \%$ plutonium. Several of the test assemblies are expected to contain fuel, which will easily offset the reduction in reactivity when using $20 \mathrm{wt} \%$ plutonium rather than the reported $20.13 \%$. In fact, it is very likely that due to the fuel contained in the test assemblies it will be necessary to load fewer than 66 driver fuel assemblies. 
Table 1. Reactor Physics Performance Characteristics of the VTR Core

\begin{tabular}{|c|c|c|}
\hline Characteristic & Unit & Value \\
\hline Core power & $\mathrm{MW}_{\text {th }}$ & 300 \\
\hline Cycle length & EFPD & 100 \\
\hline Number of batches & - & 3 to 6 \\
\hline Plutonium concentration & wt.\% & $20.14 \%$ \\
\hline Uranium enrichment & at. $\%$ & $5 \%$ \\
\hline Maximum excess reactivity & pcm & 2186 \\
\hline Test peak fast flux at BOEC & $\times 10^{15} \mathrm{n} / \mathrm{cm}^{2}-\mathrm{s}$ & 4.34 \\
\hline Test peak fast flux at EOEC & $\times 10^{15} \mathrm{n} / \mathrm{cm}^{2}-\mathrm{s}$ & 4.23 \\
\hline Absolute peak fast flux at BOEC & $\times 10^{15} \mathrm{n} / \mathrm{cm}^{2}-\mathrm{s}$ & 4.54 \\
\hline Absolute peak fast flux at EOEC & $\times 10^{15} \mathrm{n} / \mathrm{cm}^{2}-\mathrm{s}$ & 4.43 \\
\hline Average assembly power & MWth & 4.55 \\
\hline Maximum assembly power at BOEC & $\mathrm{MW}_{\text {th }}$ & 6.45 \\
\hline Maximum assembly power at EOEC & $\mathrm{MW}_{\mathrm{th}}$ & 6.17 \\
\hline Maximum absolute power variation & MWth & 0.28 \\
\hline Maximum relative power variation ${ }^{\mathrm{a}}$ & - & $7.1 \%$ \\
\hline Fuel assemblies/cycle & - & 14.9 \\
\hline Heavy metal charge/cycle & $\mathrm{kg} /$ cycle & 596.2 \\
\hline Uranium required/cycle & $\mathrm{kg} /$ cycle & 462.8 \\
\hline Plutonium required/cycle & $\mathrm{kg} /$ cycle & 133.4 \\
\hline Average discharge burnup & $\mathrm{GWd} / \mathrm{t}$ & 50.3 \\
\hline Assembly-averaged peak discharge burnup & $\mathrm{GWd} / \mathrm{t}$ & 52.5 \\
\hline Peak discharge burnup & $\mathrm{GWd} / \mathrm{t}$ & 61.0 \\
\hline
\end{tabular}

${ }^{\text {a }}$ Excluding variation in the primary control rods which is $36 \%$

\subsection{0 .000 .010 .010 .010 .000 .00}

$0.000 .010 .020 .03 \quad 0.040 .040 .030 .020 .010 .00$

$0.000 .010 .02 \quad 0.05 \quad 0.02 \quad 0.02 \quad 0.02 \quad 0.02 \quad 0.01 \quad 0.05 \quad 0.02 \quad 0.01 \quad 0.00$

$0.000 .020 .05 \quad 0.02 \quad 0.030 .04 \quad 0.04 \quad 0.04 \quad 0.04 \quad 0.03 \quad 0.020 .05 \quad 0.02 \quad 0.00$

$0.010 .030 .02 \quad 0.03 \quad 0.05 \quad 0.070 .080 .080 .08 \quad 0.06 \quad 0.05 \quad 0.03 \quad 0.01 \quad 0.030 .01$

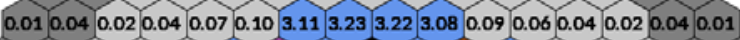

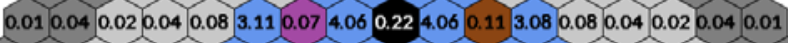

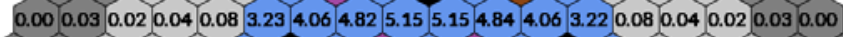

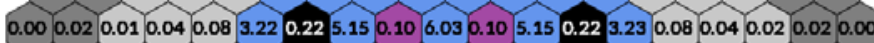

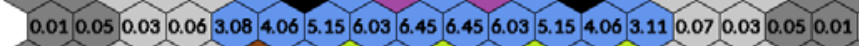

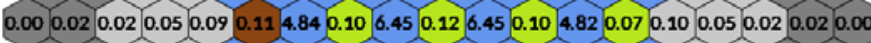

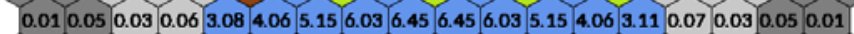

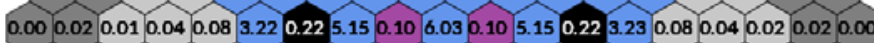

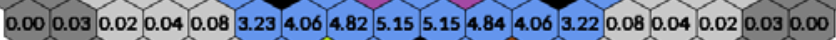

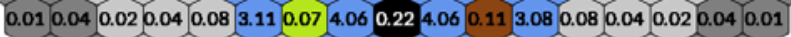

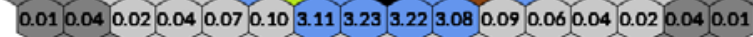

$0.010 .030 .020 .030 .050 .070 .08 \quad 0.080 .080 .060 .050 .03 \quad 0.010 .030 .01$

$0.00 \quad 0.02 \quad 0.05 \quad 0.02 \quad 0.03 \quad 0.04 \quad 0.04 \quad 0.04 \quad 0.04 \quad 0.03 \quad 0.02 \quad 0.05 \quad 0.02 \quad 0.00$

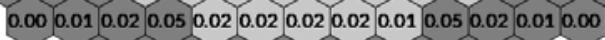

$0.000 .010 .02 \quad 0.03 \quad 0.04 \quad 0.04 \quad 0.03 \quad 0.02 \quad 0.010 .00$

0.000 .000 .010 .010 .010 .000 .00
0.000 .000 .000 .010 .000 .000 .00

$0.000 .010 .020 .030 .040 .040 .03 \quad 0.02 \quad 0.010 .00$

0.000 .010 .020 .050 .000 .000 .000 .000 .000 .050 .020 .010 .00 $0.000 .020 .050 .00 \quad 0.00 \quad 0.00 \quad 0.0000 .00 \quad 0.00 \quad 0.00 \quad 0.00 \quad 0.05 \quad 0.02 \quad 0.00$ 0.000 .030 .000 .000 .000 .010 .010 .010 .010 .010 .000 .000 .0000 .030 .00

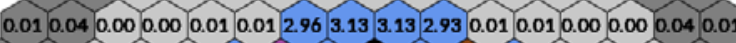
$0.000 .040 .000 .00 \quad 0.012 .960 .013 .83 \quad 0.07$ 3.83 $0.0522 .93 \quad 0.010 .000 .000 .040 .00$

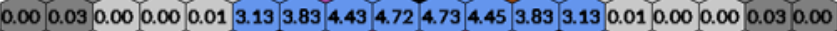

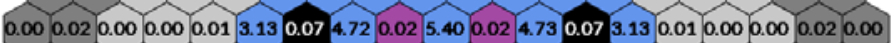

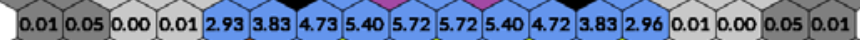

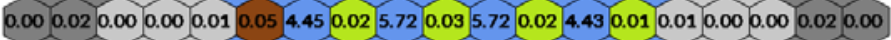

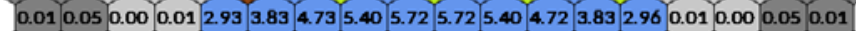

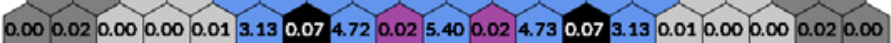

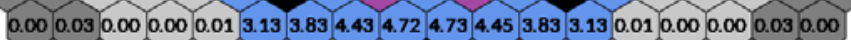

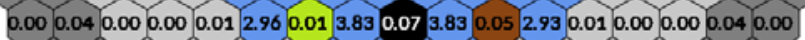

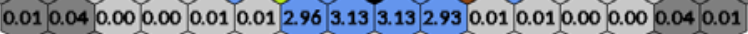
$0.000 .030 .000 .00 \quad 0.00 \quad 0.010 .010 .010 .010 .010 .000 .000 .000 .030 .00$

$0.000 .020 .050 .00 \quad 0.000 .000 .000 .000 .00 \quad 0.0000000 .050 .020 .00$

$0.000 .010 .02 \quad 0.050 .00 \quad 0.00 \quad 0.000 .00 \quad 0.000 .050 .02 \quad 0.010 .00$

$0.000 .010 .020 .030 .040 .040 .03 \quad 0.02 \quad 0.010 .00$

0.000 .000 .000 .010 .000 .000 .00

Figure 8. Total Power Distribution at BOEC (left) and EOEC (right) 


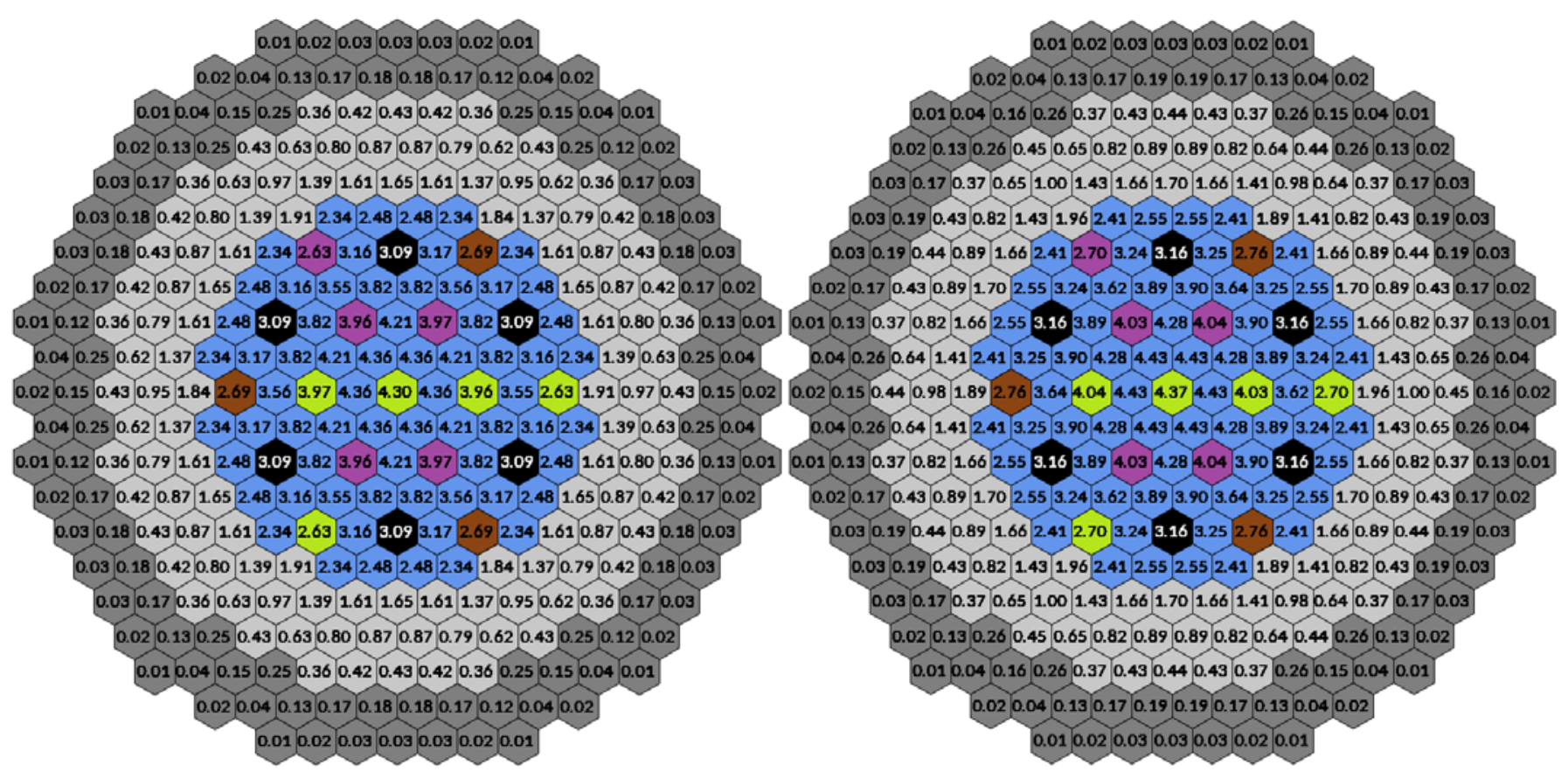

Figure 9. Peak Fast Flux Distribution at BOEC (left) and EOEC (right)

The core power, $300 \mathrm{MW}_{\text {th }}$, accounts for all sources of power within the core, in particular for fission power, neutron heating, gamma heating, and decay heat in the fuel, reflector, control, test and shield assemblies. The total power distributions at BOEC and EOEC are shown in Fig. 6. The corresponding peak fast flux achieved at BOEC and EOEC are shown in Fig. 7.

\subsection{Control Rod Worth, Reactivity Feedback and Shutdown Margins}

The reactivity worth of the control rods has been determined for the primary and secondary systems independently. The total systems worths are obtained by calculating the reactivity difference between the control rods being fully withdrawn and the control rods being fully inserted into the fuel region. The calculations were also repeated with the most reactive control rod stuck at the operating position. For the primary system evaluation, this means one rod remains at inserted about one third into the fuel region. For the secondary system evaluation, this means one rod remains fully withdrawn out of the fuel region. When using natural boron in the $\mathrm{B}_{4} \mathrm{C}$ absorber, the worths of the control systems are summarized in Table 2. Through enriching boron, these worth could be significantly increased, if deemed necessary [8].

Table 2. Primary and Secondary Reactivity Control System Worths at BOEC

\begin{tabular}{|l|c|c|}
\hline CR system & Primary & Secondary \\
\hline All rods in, pcm & 6600 & 2150 \\
\hline All rods in minus one, pcm & 5500 & 1400 \\
\hline
\end{tabular}

Reactivity coefficients have been determined for the core at equilibrium with both the. All reactivity coefficients are found to be negative, including the sodium void worth and sodium density coefficient even though plutonium-based fuel is used. This favorable outcome is due to the very large neutron 
leakage probability of the core - nearly $45 \%$ - which compensates for spectrum hardening when sodium gets voided (or its density reduced).

The shutdown worth requirements have been determined using the reactivity coefficients to determine the reactivity difference between the different states of the reactor (e.g. from hot full power to cold zero power). The approach used to determine the required worth to achieve safe shutdown of the core has been described in [9]. It is calculated that the shutdown worth requirement for the primary system is about $4300 \mathrm{pcm}$, and for the secondary system it is about $760 \mathrm{pcm}$.

The required reactivity worths of the primary and secondary control systems are lower than the calculated available worth of these systems, when assuming that the most reactive control rod is stuck at the critical position. However, the assessment performed here did not yet account for the loss of reactivity in the control systems due to boron depletion and the model use does not capture the self-shielding effects.

\subsection{Irradiation Capabilities}

The testing performance achieved with the current set of assumptions, for the various test assembly locations, are summarized in Table 3. It should be noted that the flux reported could be affect in either way by the materials or fuels loaded in the given test location.

Table 3. Summary of Irradiation Performance Characteristics

\begin{tabular}{|c|c|c|c|c|}
\hline Test assembly location & Row 1 & Row 3 & Row 5 & Reflector \\
\hline Peak fast flux, $\mathrm{n} / \mathrm{cm}^{2}-\mathrm{s}$ & $4.17 \mathrm{E}+15$ & $3.70 \mathrm{E}+15$ & $2.26 \mathrm{E}+15$ & $1.0-1.5 \mathrm{E}+15$ \\
\hline Volume with fast flux above $1 \mathrm{e} 15 \mathrm{n} / \mathrm{cm}^{2}$-s, liter & 17.7 & 17.1 & 13.8 & - \\
\hline Volume with total flux above 1e15 $\mathrm{n} / \mathrm{cm}^{2}$-s, liter & 22.2 & 21.3 & 18.7 & - \\
\hline Peak fast fluence/year, $\mathrm{n} / \mathrm{cm}^{2}$ & $1.32 \mathrm{E}+23$ & $1.17 \mathrm{E}+23$ & $7.13 \mathrm{E}+22$ & $3.0-4.5 \mathrm{E}+22$ \\
\hline Estimated dpa/year in Fe & 65 & 60 & 35 & $10-20$ \\
\hline
\end{tabular}

\section{SUMMARY}

The VTR project is a major initiative supported by the U.S. Department of Energy aiming to design and build a fast flux test reactor at one of the U.S. DOE sites by 2026. This project has been enabled by many years of work in support of advanced reactors development as well as by the recognition by the government of important capability gaps that would hinder the development of nuclear energy in the U.S.

Currently in the conceptual phase, the VTR is a 300 MWth pool-type sodium-cooled fast reactor fueled with ternary fuel bearing plutonium. The core fits into the PRISM Mod-A plant layout and will offer peak fast fluxes in excess of $4.3 \times 10^{15} \mathrm{n} / \mathrm{cm}^{2}$-s, with many test locations concurrently available, each having several liters of available testing space. All these test locations will enable achievement of over $30 \mathrm{dpa} / \mathrm{yr}$, with a maximum of $65 \mathrm{dpa} /$ year. Furthermore, the VTR will enable irradiation testing with coolants other than sodium through the cartridge loop systems without requiring any modifications.

\section{ACKNOWLEDGMENTS}

The submitted manuscript has been created by UChicago Argonne, LLC, Operator of Argonne National Laboratory ("Argonne"). Argonne National Laboratory's work was supported by the U.S. Department of Energy, Office of Nuclear Energy under contract DE-AC02-06CH11357. 
The work reported in this summary is the results of R\&D studies supporting a VTR concept, cost, and schedule estimate for DOE-NE to make a decision on procurement in the future. As such, it is preliminary.

\section{REFERENCES}

1. B. S. TRIPLETT, E. P. LOEWEN, B. J. DOOIES, PRISM: a competitive small modular sodiumcooled reactor, Nuclear Technology, 178, 186-200, May 2012

2. U.S. DEPARTMENT OF ENERGY, DOE O 413.3B Chg 5 (MinChg), Program and Project Management for the Acquisition of Capital Assets, Department of Energy, Office of Management, April 2018

3. U.S. DEPARTMENT OF ENERGY, "Secretary Perry Launches Versatile Test Reactor Project to Modernize Nuclear Research and Development Infrastructure", https://www.energy.gov/articles/secretary-perry-launches-versatile-test-reactor-project-modernizenuclear-research-and, February 28, 2019

4. F. HEIDET, ET AL., Tradeoff Studies for a Versatile Fast Spectrum Test Reactor, 2018 Pacific Basin Nuclear Conference, October 2018

5. B. FENG and F. HEIDET, Assessment of High Quality Plutonium-Fueled Core Configurations for the Versatile Test Reactor, Transaction of the 2019 American Nuclear Society Annual Meeting, June 2019, Minneapolis, MN

6. N. STAUFF and F. HEIDET, Assessment of Low Enriched Uranium Fueled Core Configurations for the Versatile Test Reactor, Transaction of the 2019 American Nuclear Society Annual Meeting, June 2019, Minneapolis, MN

7. ARC 11.0: Code System for Analysis of Nuclear Reactors, Argonne National Laboratory (2014).

8. Z. ZHONG, A. ABOU-JAOUDE and F. HEIDET, Preliminary Control Rod Lifetime Assessment for the Versatile Test Reactor, Transaction of the 2019 American Nuclear Society Annual Meeting, June 2019, Minneapolis, MN

9. F. HEIDET, Shutdown Worth Requirements for the Versatile Test Reactor, Transaction of the 2019 American Nuclear Society Winter Meeting, November 2019, Washington, DC 